\title{
AVALIAÇÃO DA QUALIDADE MICROBIOLÓGICA E FÍSICO- QUÍMICA DE QUEIJOS MATURADOS PRODUZIDOS COM LEITE CRU
}

\author{
EVALUACIÓN DE LA CALIDAD MICROBIOLÓGICA, FÍSICA Y \\ QUÍMICA DE QUESOS MADURADOS PRODUCIDOS CON LECHE \\ CRUDA
}

\section{ASSESSMENT OF MICROBIOLOGICAL AND PHYSICAL- CHEMICAL QUALITY OF MATURED CHEESES PRODUCED WITH RAW MILK}

Gisele Olivieri Soares Meier

Mestre em Medicina Veterinária, Higiene Veterinária e Processamento Tecnológico de Produtos de Origem Animal, Faculdade de Veterinária, UFF, Niterói, RJ, Brasil, ORCID: https://orcid.org/0000-0002-1015-1342, E-mail: giseleosm@gmail.com

Paula Vasconcelos Costa

Graduada em Ciências Biológicas, Técnica em Operações Farmacêuticas, Laboratório de Controle Microbiológico, Bio-Manguinhos/Fiocruz, RJ, Brasil, ORCID: https://orcid.org/0000-0002-1297-2136,E-mail: paulavasconcelosc@ gmail.com

Carla de Oliveira Rosas Doutora em Vigilância Sanitária, Tecnologista em Saúde Pública, Laboratório de Microbiologia de Alimentos e Saneantes, INCQS/Fiocruz, RJ, Brasil, ORCID: https://orcid.org/0000-0002-1991-1547, E-mail: carlaorosas23@ gmail.com

Marcelo Luiz Lima Brandão Doutor em Vigilância Sanitária, Pesquisador em Saúde Pública, Laboratório de Controle Microbiológico, Bio-Manguinhos/Fiocruz, RJ, Brasil, ORCID: https://orcid.org/0000-0003-1121-7312, E-mail: marcelo.brandao@ fiocruz.br

Marco Antônio Sloboda Cortes Doutor em Ciência e Tecnologia de Alimentos, Discente do Programa de Pós-graduação em Medicina Veterinária, Higiene Veterinária e Processamento Tecnológico de Produtos de Origem Animal, UFF, Niterói, RJ, Brasil, ORCID: https://orcid.org/0000-0003-0984-2338, E-mail: $\frac{\text { masc1971@ yahoo.com.br }}{\text { Submetido em: 22/08/2020 }}$ Aprovado em: 22/10/2020

Rev. Cient. UBM, Barra Mansa, v. 23,n. 44, 1 sem. 2021. e-ISSN 1516-4071 
MEIER, G. O. S.; COSTA, P. V.; ROSAS, C. O.; BRANDÃO, M. L. L.; CORTES, M. A. Avaliação da qualidade microbiológica e físico-química de queijos maturados produzidos com leite cru. $R$. Científica UBM Barra Mansa (RJ), ano XXVI, v. 23, n. 44, 1. Sem. 2021 p. 180-192.

ISSN 1516-4071

\section{RESUMO:}

O objetivo deste estudo foi avaliar a qualidade microbiológica e físico-química de 30 amostras de queijos maturados, produzidos com leite cru. Foram realizados os ensaios de detecção de Listeria monocytogenes e Salmonella; contagem de estafilococos coagulase positiva (ECP) e coliformes a $45^{\circ} \mathrm{C}$; e físico-químicos: umidade, gordura, gordura no extrato seco, $\mathrm{pH}$ e acidez titulável. Dezesseis $(53,3 \%)$ amostras se apresentaram fora dos padrões microbiológicos estipulados na legislação. Salmonella foi identificada em uma $(3,3 \%)$ amostra e nenhuma L. monocytogenes não foi detectada. Coliformes a $45^{\circ} \mathrm{C}$ acima de 103/g foram encontrados em $12(40,0 \%)$ amostras. Na contagem de ECP, 12 (40,0\%) amostras apresentaram contagens superior ao limite de 103/g. Nas análises físico-químicas, todos os queijos estavam fora dos padrões em pelo menos um dos parâmetros avaliados. Conclui-se que os queijos artesanais podem representar risco a população, de forma que as instituições de vigilância sanitária devem intensificar ações de controle nesta classe de produtos.

Palavras-Chave: Queijos artesanais. Listeria monocytogenes. Salmonella. coliformes. segurança de alimentos.

\section{RESUMEN:}

El objetivo de este estudio fue evaluar la calidad microbiológica y físico-química de 30 muestras de quesos curados elaborados con leche cruda. Se realizaron pruebas de detección de Listeria monocytogenes y Salmonella; recuento de estafilococos coagulasa positivos (ECP) y coliformes a $45^{\circ}$ C; y físico-químico: humedad, grasa, grasa en el extracto seco, $\mathrm{pH}$ y acidez titulable. Se encontró que dieciséis $(53,3 \%)$ muestras estaban fuera de los estándares microbiológicos estipulados en la legislación. Se identificó Salmonella en una muestra (3.3\%) y no se detectó L. monocytogenes. Se encontraron coliformes a $45^{\circ} \mathrm{C}$ por encima de $10^{3} / \mathrm{g}$ en 12 (40,0\%) muestras. En el recuento de ECP, 12 (40,0\%) muestras tenían recuentos por encima del límite de 103 / g. En los análisis físico-químicos, todos los quesos estuvieron fuera de la norma en al menos uno de los parámetros evaluados. Se concluye que los quesos artesanales pueden representar un riesgo para la población, por lo que las instituciones de vigilancia sanitaria deben intensificar las acciones de control en esta clase de productos.

Palavras Clave: Quesos artesanales. Listeria monocytogenes. Salmonela. coliformes. seguridad alimentaria.

\section{ABSTRACT:}

The objective was to evaluate the microbiological and physical-chemical quality of 30 matured cheeses produced from raw milk. Detection of Listeria monocytogenes and Salmonella; and quantification of coagulase positive staphylococcal (CPS) and coliform at $45^{\circ} \mathrm{C}$ were realized; and physical-chemical analyzes: moisture, fat, fat in the dry extract, $\mathrm{pH}$ and titratable acidity were performed. Sixteen (53.3\%) samples were out of microbiological standards. Salmonella was identified in one (3.3\%) sample and $L$. monocytogenes was not detected. Coliforms at $45^{\circ} \mathrm{C}$ above $10^{3} / \mathrm{g}$ were found in $12(40.0 \%)$ samples. Concerning the CPS quantification, 12 (40.0\%) samples presented counts higher than the limit of 103/g. Regarding physical chemical analyzes, all cheeses were out of standard in at least one parameter. It can be concluded that artisanal cheeses can represent a risk to the population, so the sanitary surveillance institutions should intensify inspection and regulation actions in this class of products.

Keywords: Artisanal cheeses. Listeria monocytogenes. Salmonella. coliforms. food security 
MEIER, G. O. S.; COSTA, P. V.; ROSAS, C. O.; BRANDÃO, M. L. L.; CORTES, M. A. Avaliação da qualidade microbiológica e físico-química de queijos maturados produzidos com leite cru. $R$. Científica UBM - Barra Mansa (RJ), ano XXVI, v. 23, n. 44, 1. Sem. 2021 p. 180-192.

ISSN 1516-4071

\section{INTRODUÇÃO}

No Brasil, o consumo de produtos artesanais aumentou nos últimos anos devido ao crescente movimento para uma alimentação com maior qualidade, dando atenção a sustentabilidade e ao bem-estar animal, aliado a iniciativas governamentais (SANTOS et al., 2016; CAMPAGNOLLO et al., 2018; CARVALHO et al., 2019). Segundo o último censo agropecuário, a produção de queijo da agroindústria rural da região sudeste é de aproximadamente 51 mil toneladas, sendo o estado do Rio de Janeiro responsável por 2,2 mil toneladas (IBGE, 2019).

Os queijos artesanais são produzidos a partir de leite cru (CARVALHO et al., 2019). Nesse processo ocorrem reações devido aos microrganismos naturais presentes no leite, gerando as características sensoriais encontradas no produto final. Devido à ausência de processamento térmico do leite, os queijos artesanais podem apresentar um risco a saúde pública, caso microrganismos patogênicos estejam presentes e não sejam eliminados até níveis seguros. Dessa forma, a aquisição de uma matéria-prima de qualidade, associado a adoção de boas práticas de fabricação (BPF) e higiene são primordiais para qualidade microbiológica do produto final (SANTOS et al., 2016; CARVALHO et al., 2019).

De acordo com os dados do Boletim Epidemiológico de surtos de doenças transmitidas por alimentos (DTA) no Brasil, o leite e os derivados lácteos foram responsáveis por 7,29\% dos surtos de DTA no período de 2009 a 2018 (BRASIL, 2019). Uma pesquisa realizada pela Food Standards Australia New Zealand (FSANZ, 2009), revelou que o queijo produzido com leite cru está associado a casos de DTA, associados a diversas bactérias, como: Escherichia coli O157:H7, Listeria monocytogenes, Salmonella spp., e Staphylococcus aureus. O Centro de Prevenção e Controle de Doenças dos Estados Unidos da América, entre 1998 e 2011, identificou 38 surtos de DTA relacionados ao consumo de queijo produzido com leite não pasteurizado. Esses surtos acometeram um total de 816 indivíduos, gerando 168 hospitalizações e três óbitos (GOULD et al., 2014).

A legislação brasileira proibia a produção de queijos artesanais com períodos menores de 60 dias de maturação (BRASIL, 1996), sendo alterada em 2013 pela Instrução Normativa (IN) n. ${ }^{\circ} 30$ do Ministério da Agricultura, Pecuária e Abastecimento (Mapa). Segundo a IN, é permitido a maturação de queijos artesanais por um período inferior a 60 dias, desde que se apresentem estudos técnico-científicos que comprovem a inocuidade do produto (BRASIL, 2013). 
MEIER, G. O. S.; COSTA, P. V.; ROSAS, C. O.; BRANDÃO, M. L. L.; CORTES, M. A. Avaliação da qualidade microbiológica e físico-química de queijos maturados produzidos com leite cru. $R$. Científica UBM Barra Mansa (RJ), ano XXVI, v. 23, n. 44, 1. Sem. 2021 p. 180-192.

ISSN 1516-4071

No âmbito da legislação federal brasileira, o regulamento de Inspeção Industrial e Sanitária dos Produtos de Origem Animal (RIISPOA) do Mapa é utilizado para regulamentação da produção de queijo artesanal. Entretanto, os critérios estipulados demandam um alto investimento em infraestrutura e formação dos profissionais, não sendo a realidade de pequenos produtores que entram para informalidade (SANTOS et al., 2016). Com o propósito de solucionar essa questão, encontra-se em discussão na Assembleia Legislativa do Estado do Rio de Janeiro o projeto de Lei no 893/2019 que tem como objetivo incentivar os produtores rurais, estabelecer diretrizes para produção artesanal e garantir a segurança alimentar (ALERJ, 2019).

Tendo em vista o risco que os queijos artesanais possam apresentar à saúde da população, o objetivo desde estudo foi avaliar a qualidade microbiológica e físico-química de queijos artesanais, contribuindo com revisões das legislações normativas voltadas para a segurança destes alimentos no estado

\section{MATERIAIS E MÉTODOS}

\subsection{AMOSTRAS}

Foram analisadas 30 amostras de queijos artesanais obtidos em feiras, produtores e mercados varejistas do estado do Rio de Janeiro. As amostras foram coletadas e transportadas em temperatura ambiente até o laboratório e foram mantidas a temperatura de $2-8^{\circ} \mathrm{C}$ até o momento da análise.

\section{2 .2 ANÁLISES MICROBIOLÓGICAS}

As análises microbiológicas foram realizadas com base nos critérios preconizados na RDC n. ${ }^{\circ}$ 12/2001 (ANVISA, 2001) para queijos de média umidade. Os ensaios microbiológicos foram realizados de acordo com as metodologias descritas no Bacteriological Analytical Manual / Food and Drug Administration (BAM/FDA). Foram realizados os ensaios de pesquisa de Salmonella spp. (ANDREWS et al., 2020) e de L. monocytogenes (HITCHINS et al., 2017) pelas técnicas de enriquecimento-seletivo; e a quantificação de estafilococos coagulase positiva (ECP) pela técnica do número mais provável (NMP) (TALLENT et al., 2016) e coliformes a $45^{\circ} \mathrm{C}$ pela técnica de contagem em placas (FENG et al., 2017).

Os seguintes microrganismos foram utilizados como controles nas metodologias: $L$. monocytogenes INCQS 266 (ATCC 7644), L. innocua INCQS 354 (ATCC 33090), L. ivanovii INCQS 355 (ATCC 19119), Enterococcus faecalis INCQS 017 (ATCC 4083), Klebsiella pneumoniae INCQS 147 (ATCC 13883), E. coli INCQS 0033 (ATCC 25922), Pseudomonas 
MEIER, G. O. S.; COSTA, P. V.; ROSAS, C. O.; BRANDÃO, M. L. L.; CORTES, M. A. Avaliação da qualidade microbiológica e físico-química de queijos maturados produzidos com leite cru. $R$. Científica UBM - Barra Mansa (RJ), ano XXVI, v. 23, n. 44, 1. Sem. 2021 p. 180-192.

ISSN 1516-4071

aeroginosa INCQS 0099 (ATCC 27853), Staphylococcus aureus INCQS 013 (ATCC 65038) e Kocuria rhizophila INCQS 011 (ATCC 9341).

Para interpretação dos resultados, foram comparados os valores encontrados nas análises com os estabelecidos na RDC n..$^{\circ}$ 12/2001 (Quadro 1) e as amostras foram classificadas como em condições sanitárias satisfatórias ou insatisfatórias.

Quadro 1- Padrão microbiológico sanitário para queijos artesanais segundo a Resolução da Diretoria Colegiada n ${ }^{\circ}$ 12/2001 (ANVISA, 2001).

\begin{tabular}{|c|c|c|}
\hline 8.B - Queijos & Micro-organismo(s) & $\begin{array}{c}\text { Tolerância para amostra } \\
\text { indicativa }\end{array}$ \\
\hline b) de média umidade: $36 \%<$ umid $<$ & Coliformes a $45^{\circ} \mathrm{C} / \mathrm{g}$ & $10^{3}$ \\
$46 \%$ (Danbo, pategrás sandwich, & Estafilococos & $10^{3}$ \\
\cline { 2 - 3 } prato, tandil, tilsit, tybo, mussarela & coagulase positiva/g & \\
\cline { 2 - 3 } (mozzarella, muzzarella) curado e & Salmonella $\mathrm{sp} . / 25 \mathrm{~g}$ & Ausência \\
\cline { 2 - 3 } similares) e de queijo ralado e em pó & L. monocytogenes $/ 25 \mathrm{~g}$ & Ausência \\
\hline
\end{tabular}

\subsection{ANÁLISES FÍSICO-QUÍMICAS}

As análises físico-químicas foram realizadas de acordo com a IN n. ${ }^{\circ}$ 68/2006 (BRASIL, 2006), sendo avaliados os teores de umidade (IDF, 1993), gordura e gordura extrato seco (GES) (PREGNOLATTO, 1985), pH (BRASIL, 1981) e da acidez titulável (MERCK, 1993). Os queijos foram classificados quanto GES como: extra gordo ( $\geq 60 \%)$, gordo $(45-59,9 \%)$, semigordo (25-44,9\%) e magro (10-24,9\%). Com relação ao teor de umidade, foram classificados como alta umidade $(\geq 46 \%)$, média umidade $(45,9-36 \%)$ e baixa umidade $(\leq$ $35,9 \%)$.

\section{RESULTADOS}

Os resultados das análises microbiológicas e físico-químicas estão apresentados na Tabela 1. Dezesseis $(53,3 \%)$ amostras foram consideradas insatisfatórias: 12 (40,0\%) devido a contagem de coliformes a $45^{\circ} \mathrm{C}$ acima de $10^{3} \mathrm{UFC}_{\mathrm{g}} \mathrm{g}^{-1}, 12(40,0 \%)$ devido a contagem de ECP $>1.100 \mathrm{NMP} / \mathrm{g}^{-1}$, e uma $(3,3 \%)$ devido a contaminação por Salmonella spp. Nenhuma amostra apresentou contaminação por L. monocytogenes. Dezesseis $(53,3 \%)$ amostras foram 
MEIER, G. O. S.; COSTA, P. V.; ROSAS, C. O.; BRANDÃO, M. L. L.; CORTES, M. A. Avaliação da qualidade microbiológica e físico-química de queijos maturados produzidos com leite cru. $R$. Científica UBM Barra Mansa (RJ), ano XXVI, v. 23, n. 44, 1. Sem. 2021 p. 180-192.

ISSN 1516-4071

classificadas como de baixa umidade, $11(36,7 \%)$ de média umidade, e três $(10,0 \%)$ de alta umidade.

Tabela 1 - Resultados das análises microbiológicas das 30 amostras de queijos artesanais.

\begin{tabular}{|c|c|c|c|}
\hline $\begin{array}{l}\text { N. }{ }^{\circ} \text { da amostra } \\
\text { (Tempo de } \\
\text { maturação-dias) }\end{array}$ & Salmonella spp./25 g & Coliformes a $45^{\circ} \mathrm{C}^{\mathrm{a}} / \mathrm{g}$ & $\begin{array}{c}\text { Estafilococos } \\
\text { coagulase positiva }{ }^{\mathrm{b}} / \mathrm{g}\end{array}$ \\
\hline $1(30)$ & Presença & $1,0 \times 10^{5}$ & $>1100$ \\
\hline $2(30)$ & Ausência & $2,1 \times 10^{4}$ & 36 \\
\hline $3(30)$ & Ausência & $7,0 \times 10^{1}$ & 15 \\
\hline $4(30)$ & Ausência & $8,4 \times 10^{4}$ & $>1100$ \\
\hline $5(15)$ & Ausência & $7,7 \times 10^{3}$ & 75 \\
\hline $6(7)$ & Ausência & $1,4 \times 10^{5}$ & 43 \\
\hline $7(10)$ & Ausência & $1,5 \times 10^{5}$ & $>1100$ \\
\hline $8(60)$ & Ausência & $1,2 \times 10^{4}$ & 3 \\
\hline $9(15)$ & Ausência & $1,5 \times 10^{4}$ & $>1100$ \\
\hline $10(15)$ & Ausência & $1,3 \times 10^{5}$ & $>1100$ \\
\hline $11(30)$ & Ausência & $1,5 \times 10^{5}$ & $>1100$ \\
\hline $12(15)$ & Ausência & $7,0 \times 10^{2}$ & $>1100$ \\
\hline $13(10)$ & Ausência & $6,5 \times 10^{4}$ & $>1100$ \\
\hline $14(40)$ & Ausência & $3,8 \times 10^{2}$ & $<3$ \\
\hline $15(60)$ & Ausência & $<10^{1}$ & $<3$ \\
\hline $16(30)$ & Ausência & $<10^{1}$ & 3,6 \\
\hline $17(22)$ & Ausência & $<10^{1}$ & $>1100$ \\
\hline $18(22)$ & Ausência & $<10^{1}$ & 11 \\
\hline $19(22)$ & Ausência & $<10^{1}$ & 3 \\
\hline $20(22)$ & Ausência & $<10^{1}$ & 240 \\
\hline $21(22)$ & Ausência & $<10^{1}$ & 9,2 \\
\hline $22\left(\mathrm{NI}^{\mathrm{c}}\right)$ & Ausência & $3,7 \times 10^{5}$ & $>1100$ \\
\hline $23(60)$ & Ausência & $<10^{1}$ & 3 \\
\hline $24(60)$ & Ausência & $6,5 \times 10^{1}$ & 21 \\
\hline $25(\mathrm{NI})$ & Ausência & $<10^{1}$ & 3 \\
\hline $26(\mathrm{NI})$ & Ausência & $1,8 \times 10^{3}$ & $>1100$ \\
\hline $27(\mathrm{NI})$ & Ausência & $2,5 \times 10^{1}$ & $>1100$ \\
\hline
\end{tabular}


MEIER, G. O. S.; COSTA, P. V.; ROSAS, C. O.; BRANDÃO, M. L. L.; CORTES, M. A. Avaliação da qualidade microbiológica e físico-química de queijos maturados produzidos com leite cru. $R$. Científica UBM - Barra Mansa (RJ), ano XXVI, v. 23, n. 44, 1. Sem. 2021 p. 180-192.

ISSN 1516-4071

\begin{tabular}{cccc}
$28(\mathrm{NI})$ & Ausência & $<10^{1}$ & 3 \\
$29(\mathrm{NI})$ & Ausência & $<10^{1}$ & 6,2 \\
$30(\mathrm{NI})$ & Ausência & $<10^{1}$ & 3,6 \\
\hline Total $(\mathbf{n}=\mathbf{3 0})$ & $\mathbf{1 / 3 0}(\mathbf{3 , 3})$ & $\mathbf{1 2 / 3 0}(\mathbf{4 0 . 0 \%})$ & $\mathbf{1 2 / 3 0}(\mathbf{4 0 . 0 \%})$
\end{tabular}

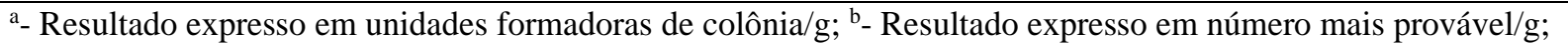
c- Não informado.

Tabela 2 - Resultados das análises físico-químicas das 30 amostras de queijos artesanais.

\begin{tabular}{|c|c|c|c|c|c|}
\hline $\begin{array}{c}\text { N. } .^{\circ} \text { da amostra } \\
\text { (Tempo de } \\
\text { maturação-dias) }\end{array}$ & Umidade $(\%)$ & Gordura (\%) & $\begin{array}{c}\text { Gordura } \\
\text { extrato seco } \\
(\%)\end{array}$ & $\mathrm{pH}$ & $\begin{array}{l}\text { Acidez }(\mathrm{g} \\
\text { ácido } \\
\text { lático/100g) }\end{array}$ \\
\hline $1(30)$ & 31,70 & 28,75 & 19,64 & 5,47 & 0,15 \\
\hline $2(30)$ & 33,00 & 28,50 & 19,10 & 5,40 & 0,12 \\
\hline $3(30)$ & 33,00 & 28,50 & 19,10 & 5,33 & 0,14 \\
\hline $4(30)$ & 41,00 & 29,00 & 17,11 & 5,31 & 0,10 \\
\hline $5(15)$ & 41,00 & 21,25 & 12,54 & 5,26 & 0,13 \\
\hline $6(7)$ & 47,00 & 26,50 & 14,05 & 4,70 & 0,17 \\
\hline $7(10)$ & 34,00 & 30,00 & 19,80 & 5,60 & 0,06 \\
\hline $8(60)$ & 29,00 & 26,00 & 18,46 & 6,08 & 0,03 \\
\hline $9(15)$ & 37,00 & 29,50 & 18,59 & 5,30 & 0,15 \\
\hline $10(15)$ & 32,00 & 23,00 & 15,64 & 5,43 & 0,06 \\
\hline $11(30)$ & 31,00 & 28,00 & 19,32 & 5,46 & 0,09 \\
\hline $12(15)$ & 45,60 & 29,50 & 16,05 & 5,30 & 0,09 \\
\hline $13(10)$ & 42,00 & 28,50 & 16,53 & 6,05 & 0,05 \\
\hline $14(40)$ & 19,00 & 25,50 & 20,66 & 5,87 & 0,09 \\
\hline $15(60)$ & 20,80 & 36,50 & 28,91 & 5,60 & 0,10 \\
\hline $16(30)$ & 17,90 & 26,00 & 21,35 & 5,73 & 0,06 \\
\hline $17(22)$ & 37,40 & 30,50 & 19,09 & 5,77 & 0,15 \\
\hline $18(22)$ & 24,00 & 28,00 & 21,28 & 5,61 & 0,19 \\
\hline $19(22)$ & 27,40 & 31,50 & 22,87 & 5,47 & 0,17 \\
\hline $20(22)$ & 32,80 & 33,00 & 22,18 & 5,70 & 0,09 \\
\hline $21(22)$ & 18,70 & 31,25 & 25,41 & 5,57 & 0,10 \\
\hline $22\left(\mathrm{NI}^{\mathrm{a}}\right)$ & 52,00 & 22,00 & 10,56 & 6,37 & 0,12 \\
\hline
\end{tabular}


MEIER, G. O. S.; COSTA, P. V.; ROSAS, C. O.; BRANDÃO, M. L. L.; CORTES, M. A. Avaliação da qualidade microbiológica e físico-química de queijos maturados produzidos com leite cru. $R$. Científica UBM Barra Mansa (RJ), ano XXVI, v. 23, n. 44, 1. Sem. 2021 p. 180-192.

ISSN 1516-4071

$\begin{array}{llllll}23(60) & 38,00 & 26,00 & 16,12 & 5,70 & 0,29 \\ 24(60) & 41,00 & 26,00 & 15,34 & 5,13 & 0,10 \\ 25(\mathrm{NI}) & 39,00 & 24,00 & 14,64 & 5,77 & 0,17 \\ 26(\mathrm{NI}) & 49,00 & 23,00 & 11,73 & 5,57 & 0,09 \\ 27(\mathrm{NI}) & 46,00 & 20,00 & 10,80 & 4,77 & 0,18 \\ 28(\mathrm{NI}) & 29,00 & 37,00 & 26,27 & 5,83 & 0,11 \\ 29(\mathrm{NI}) & 36,00 & 23,00 & 14,72 & 6,07 & 0,19 \\ 30(\mathrm{NI}) & 26,00 & 27,50 & 20,35 & 5,57 & 0,13\end{array}$

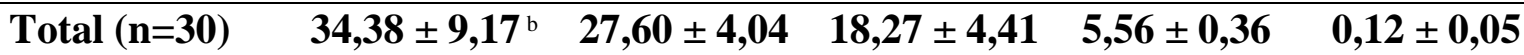

a - Não informado; ${ }^{b}$ Resultados expresso em média \pm desvio-padrão.

O valor médio de gordura encontrado foi de 27,60 ^4,04\%; o teor de GES foi de 18,27 $\pm 4,40 \%$. Sete $(23,3 \%)$ amostras apresentaram resultado inferior a $24,90 \%$, sendo consideradas queijos magros; $23(76,7 \%)$ apresentaram resultados abaixo de $44,90 \%$ e foram classificadas como queijos semigordos. O pH médio das amostras foi de 5,56 \pm 0,36 (valor máximo de 6,37 e mínimo de 4,70). Já a acidez titulável, apresentou média de 0,12 \pm 0,05 (valor máximo de 0,29 e mínimo de 0,03)

\section{DISCUSSÃO}

A ocorrência de Salmonella spp. encontrada neste estudo (3,3\%), mesmo baixa, é preocupante. Esse patógeno tem origem alimentar, podendo causar desde infecções como gastroenterites a quadros graves como a febre tifoide (ANDREWS et al., 2020). A ocorrência do patógeno foi inferior à de outros estudos no Brasil, tendo a ocorrência variando de 5,5 a 26,7\% (FEITOSA et al., 2003; DUARTE et al., 2005; SANTANA et al., 2008). Surtos de salmonelose já foram associados ao leite e seus derivados, ocorrendo em diversos países (FSANZ, 2009, GOULD et al., 2014; ROBINSON et al., 2018). No Brasil, Salmonella spp. é o segundo principal agente etiológico identificado em surtos de DTA, sendo responsável por $11,2 \%$ dos casos (BRASIL, 2019).

Coliformes a $45^{\circ} \mathrm{C}$ foi responsável pelos maiores índices de reprovação (Tabela 1). Este resultado foi semelhante ao relatado por Perin e colaboradores (2017) ao analisarem 15 amostras de queijos artesanais, no estado de Minas Gerais; observaram 20\% com contagem de coliformes acima de $10^{3} / \mathrm{g}$. Bactérias do grupo dos coliformes a $45^{\circ} \mathrm{C}$ são utilizados como indicadores de contaminação de origem fecal e sua presença indicam falhas nas BPF e higiene durante a cadeia produtiva (FENG et al., 2017). 
MEIER, G. O. S.; COSTA, P. V.; ROSAS, C. O.; BRANDÃO, M. L. L.; CORTES, M. A. Avaliação da qualidade microbiológica e físico-química de queijos maturados produzidos com leite cru. $R$. Científica UBM - Barra Mansa (RJ), ano XXVI, v. 23, n. 44, 1. Sem. 2021 p. 180-192.

ISSN 1516-4071

O período de maturação parece ter influenciado na presença de coliformes. As amostras 6, 7 e 13, que possuíam período de maturação <10 dias, apresentaram elevada concentração de coliformes $\left(>10^{4} / \mathrm{g}\right)$. Dessa forma, os procedimentos de produção, incluindo o tempo de maturação, devem ser padronizados de forma a eliminar estes contaminantes caso presentes na matéria-prima ou introduzidos ao longo do processo.

A ocorrência de ECP, principalmente de $S$. aureus, é frequente em queijos artesanais, e representa um risco à saúde humana, devido a possível produção de enterotoxinas, levando a intoxicação alimentar (ROSA et al., 2015). Neste trabalho, a presença de ECP pode estar relacionada ao alto teor de umidade presente. Das 12 amostras insatisfatórias, oito apresentaram teor de umidade $\geq 36 \%$, sendo consideradas de média a alta umidade. A umidade interfere no teor da atividade de água (Aa) e nas atividades metabólicas dos microrganismos, favorecendo o crescimento (CECCHI, 2003). A presença de ECP pode ser oriunda do leite, devido a casos de mastites no gado leiteiro, contaminando o leite (SAHEBEKHTIARI et al., 2011). Além disso, a contaminação pode ocorrer pós-produção, por intermédio do ambiente, utensílios e manipuladores, uma vez que estas bactérias podem estar presentes na microbiota de humanos (ROSA et al., 2015; TALLENT et al., 2016).

L. monocytogenes não foi isolada nos queijos analisados, corroborando com dados de ocorrência de outros estudos realizados no Brasil totalizando mais de 272 amostras analisadas (DORES et al., 2013; MARTINS et al., 2015).

Neste estudo, a amostra 22 foi identificada com o maior teor de umidade $(52,0 \%)$ e o maior valor de $\mathrm{pH}(6,37)$, resultando na maior taxa de coliformes $\left(3,7 \times 10^{5}\right)$ e contagem de ECP >1.100 NMP/g-1 (Tabela 1). A determinação do pH em queijos pode indicar o grau de deterioração do produto, sendo um fator importante na determinação da preservação desse alimento. Os queijos com $\mathrm{pH}$ mais próximo de 7,0 e umidade elevada possuem o ambiente mais favorável para o desenvolvimento da maioria dos microrganismos (CECCHI, 2003).

Os resultados das análises físico-químicas foram heterogêneos (Tabela 1). Mesmo sendo todas as amostras comercializadas como queijos artesanais, apresentam diferenças na composição do leite, tecnologia de fabricação, tempo de maturação, entre outros fatores.

\section{CONSIDERAÇÕES FINAIS}

As análises microbiológicas mostraram que mais da metade das amostras estavam em condições sanitárias insatisfatórias. Os queijos artesanais avaliados apresentaram parâmetros 
MEIER, G. O. S.; COSTA, P. V.; ROSAS, C. O.; BRANDÃO, M. L. L.; CORTES, M. A. Avaliação da qualidade microbiológica e físico-química de queijos maturados produzidos com leite cru. $R$. Científica UBM Barra Mansa (RJ), ano XXVI, v. 23, n. 44, 1. Sem. 2021 p. 180-192.

ISSN 1516-4071

físico-químicos diversos, indicando que os processos de produção parecem ser heterogêneos dentre os produtores.

Sugere-se que os órgãos regulamentadores padronizem as técnicas de produção desse tipo de queijos, de forma a obter alimentos mais harmonizados entre os produtores e que estipule um tempo de maturação mínimo, ou mesmo fixo, que garanta a eliminação de microrganismos patogênicos de forma a ofertar produtos de maior qualidade à população. Devido ao número elevado $(53,3 \%)$ de amostras insatisfatórias, sugere-se que os órgãos de Vigilância Sanitária intensifiquem ações de fiscalização nessa classe de produtos, de forma a evitar que estes venham a causar danos à saúde dos consumidores

\section{AGRADECIMENTOS}

Ao Programa de Pós-graduação em Medicina Veterinária, Higiene Veterinária e Processamento Tecnológico de Produtos de Origem Animal da Universidade Federal Fluminense da qual Gisele Meier foi aluna de Mestrado. Ao INCQS/Fiocruz pela parceria neste projeto.

\section{REFERÊNCIAS}

AGÊNCIA NACIONAL DE VIGILÂNCIA SANITÁRIA - ANVISA. Resolução de Diretoria Colegiada (RDC) $n^{\circ} 12$ de 02 de Janeiro de 2001. Aprova o regulamento técnico sobre padrões microbiológicos para alimentos. Diário Oficial União. 02 jan 2001.

ANDREWS, W.; et al. Salmonella. In: Food \& Drug Administration Center for Food Safety \& Applied Nutrition. Bacteriological Analytical Manual. Estados Unidos, 2020. Livro digital. (1 recurso online). Disponível em:

https://www.fda.gov/food/laboratory-methods-food/bam-chapter-5-salmonella. Acesso em: 20 jun. 2020

ASSEMBLEIA LEGISLATIVA DO ESTADO DO RIO DE JANEIRO - ALERJ. Projeto de Lei 893 no 893 de 2019. Dispõe sobre a produção e a comercialização dos queijos artesanais do estado do Rio de Janeiro regulamentando o artigo 10 -a da lei federal $\mathrm{n}^{\circ} 1.283$ de 18 de dezembro de 1950 e o decreto federal $n^{\circ} 9.918$ de 18 de julho de 2019. Departamento de arquivo da ALERJ. 2019.

BRASIL. Ministério da Agricultura. Métodos analíticos oficiais para controle de produtos de origem animal e seus ingredientes. Brasil: LANARA, 1981.

BRASIL. Ministério da Agricultura. Portaria no 146, de 07 de março de 1996. Aprova os regulamentos técnicos de identidade e qualidade dos produtos lácteos. Diário Oficial da República Federativa do Brasil. 07 mar 1996. 
MEIER, G. O. S.; COSTA, P. V.; ROSAS, C. O.; BRANDÃO, M. L. L.; CORTES, M. A. Avaliação da qualidade microbiológica e físico-química de queijos maturados produzidos com leite cru. $R$. Científica UBM - Barra Mansa (RJ), ano XXVI, v. 23, n. 44, 1. Sem. 2021 p. 180-192.

ISSN 1516-4071

BRASIL. Ministério da Agricultura, Pecuária e Abastecimento. Instrução Normativa $\mathrm{n}^{\circ} 68$ de 12 de dezembro de 2006. Oficializa os métodos analíticos oficiais físico-químicos para controle de leite e produtos lácteos. Brasília, DF: Ministério da Agricultura, Pecuária e Abastecimento, 2006.

BRASIL. Ministério da Agricultura, Pecuária e Abastecimento. Instrução normativa $\mathrm{n}^{\circ} 30$, de 7 de agosto de 2013. Revoga a Instrução normativa n ${ }^{\circ}$ 57. Diário Oficial União. 08 ago 2013.

BRASIL. Ministério da Saúde. Secretaria de Vigilância em Saúde. Surtos de doenças transmitidas por alimentos no Brasil. Brasília, DF: Ministério da Saúde, 2019.

CAMPAGNOLLO, F.; et al. Selection of indigenous lactic acid bacteria presenting anti-listerial activity, and their role in reducing the maturation period and assuring the safety of traditional Brazilian cheeses. Food Microbiology, v.73, p. 288-297, agosto/2018. ISSN 1095-9998

CARVALHO, M.; et al. Traditional Colonial-type cheese from the south of Brazil: A case to support the new Brazilian laws for artisanal cheese production from raw milk. Journal of Dairy Science, v.102, n.11, p. 9711-9720, agosto/2019. ISSN 1525-3198

CECCHI, H. Fundamentos teóricos e práticos em análise de alimentos. 1. ed. Campinas: Editora da Unicamp, 2003. 208 p.

DORES, M. T.; NÓBREGA, J.; FERREIRA, C. Room temperature aging to garantee microbiological safety of Brazilian artisan Canasta cheese. Food Science and Technology, Campinas, v. 33, n.1, p. 180-185, fevereiro/2013. ISSN 0101-2061

DUARTE, D.; et al. Pesquisa de Listeria monocytogenes e microrganismos indicadores higiênico-sanitários em queijo de coalho produzido e comercializado no estado de Pernambuco. Arquivo do Instituto Biológico, São Paulo, v.72, n.3, p. 297-302, setembro/2005. ISSN 18081657

FEITOSA, T.; et al. Pesquisa de Salmonella sp., Listeria sp., e microrganismos indicadores higiênico sanitários em queijos produzidos no estado do Rio Grande do Norte. Ciência e Tecnologia de Alimentos (Online), Campinas, v.23, p. 162-165, dezembro/2003. e-ISSN $1678-457 \mathrm{X}$

FENG, P.; et al. Enumeration of E. coli and coliform bacteria. In: Food \& Drug Administration Center for Food Safety \& Applied Nutrition. Bacteriological Analytical Manual. Estados Unidos, 2017. Livro digital. (1 recurso online). Disponível em: https://www.fda.gov/food/laboratory-methods-food/bam-chapter-4-enumeration-escherichiacoli-and-coliform-bacteria. Acesso em: 20 jun. 2020.

FOOD STANDARDS AUSTRALIA NEW ZEALAND - FSANZ. Microbiological risk assessment of raw milk cheese: Risk assessment microbiology section. Nova Zelândia: Food Standards Australia New Zealand, 2009. 113 p.

GOULD, L.; MUNGAI, E.; BEHRAVESH, C. Outbreaks Attributed to Cheese: Differences Between Outbreaks Caused by Unpasteurized and Pasteurized Dairy Products, United States, 
MEIER, G. O. S.; COSTA, P. V.; ROSAS, C. O.; BRANDÃO, M. L. L.; CORTES, M. A. Avaliação da qualidade microbiológica e físico-química de queijos maturados produzidos com leite cru. R. Científica UBM Barra Mansa (RJ), ano XXVI, v. 23, n. 44, 1. Sem. 2021 p. 180-192.

ISSN 1516-4071

1998-2011. Foodborne Pathogens and Disease, v.11, n.7, p. 545-551, abril/2014. e-ISSN $1556-7125$

HITCHINS, A.; JINNEMAN, K.; CHEN, Y. Detection of Listeria monocytogenes in Foods and Environmental Samples, and Enumeration of Listeria monocytogenes in Foods. In: Food \& Drug Administration Center for Food Safety \& Applied Nutrition. Bacteriological Analytical Manual. Estados Unidos, 2017. Livro digital. (1 recurso online). Disponível em: https://www.fda.gov/food/laboratory-methods-food/bam-chapter-10-detection-listeriamonocytogenes-foods-and-environmental-samples-and-enumeration. Acesso em: 19 jun. 2020.

INSTITUTO BRASILEIRO DE GEOGRAFIA E ESTATÍSTICA - IBGE. Censo agropecuário 2018. Brasília: Instituto Brasileiro de Geografia e Estatística, 2019.

INTERNATIONAL DAIRY FEDERATION - IDF. Dried milk and dried cream: Determination of water contente. Bélgica: International Dairy Federation, 1993.

MARTINS, J.; et al. Determining the minimum ripening time of artisanal Minas cheese, a traditional Brazilian cheese. Brazilian Journal of Microbiology, São Paulo, v.46, n.1, p. 219230, março/2015. ISSN 1678-4405

MERCK. Reactivos, diagnóstica, productos químicos. Darmestádio, 1993. 1584 p.

PERIN, L.; et al. Bacterial ecology of artisanal Minas cheeses assessed by culture-dependent and independent methods. Food Microbiology, v. 65, p. 160-169, agosto/2017. ISSN 07400020

INSTITUTO ADOLFO LUTZ. Queijo, manteiga, margarina e extrato de soja In: PREGNOLATTO, W. Normas analíticas do Instituto Adolfo Lutz: métodos químicos e físicos para análise de alimentos. São Paulo: Instituto Adolfo Lutz, 1985.

ROBINSON, E.; et al. Outbreak of Salmonella Newport associated with internationally distributed raw goats' milk cheese, France, 2018. Epidemiology \& Infection, p. 1-23, maio/2020. e-ISSN 1469-4409

ROSA, D.; et al. Detecção de genes toxigênicos, susceptibilidade antibiograma e antagonismo in vitro de Staphylococcus spp. isolados de queijos artesanais. Vigilância Sanitária em Debate, Rio de Janeiro, v.3, n.1, p. 37-42, fevereiro/2015. ISSN 2317-269X

SAHEBEKHTIARI, N.; et al. Characterization of Staphylococcus aureus strains isolated from raw milk of bovine subclinical mastitis in Tehran and Mashhad. Acta Microbiologica et Immulogica Hungarica, Budapeste, v.58, n.2, p. 113-121, junho/2011. e-ISSN 1588-2640

SANTANA, R.; et al. Qualidade microbiológica de queijo-coalho comercializado em Aracaju, SE. Arquivo Brasileiro de Medicina Veterinária e Zootecnia, v. 60, n. 6, p. 1517-1522, 2008. ISSN 1678-4162

SANTOS, J.; et al Dilemas e desafios para circulação de queijos artesanais no Brasil. Vigilância Sanitária em Debate, Rio de Janeiro, v.4, n.4, p. 13-22, novembro/2016. ISSN 2317-269X 
MEIER, G. O. S.; COSTA, P. V.; ROSAS, C. O.; BRANDÃO, M. L. L.; CORTES, M. A. Avaliação da qualidade microbiológica e físico-química de queijos maturados produzidos com leite cru. $R$. Científica UBM - Barra Mansa (RJ), ano XXVI, v. 23, n. 44, 1. Sem. 2021 p. 180-192.

ISSN 1516-4071

TALLENT, S.; et al. Staphylococcus aureus. In: Food \& Drug Administration Center for Food Safety \& Applied Nutrition. Bacteriological Analytical Manual. Estados Unidos, 2016. Livro digital. (1 recurso online). Disponível em:

https://www.fda.gov/food/laboratory-methods-food/bam-chapter-12-staphylococcus-aureus. Acesso em: 21 jun. 2020. 